\title{
PEMODELAN DAN SIMULASI KINERJA PIN UJI BAHAN BAKAR PWR DENGAN UO ${ }_{2}$ DIPERKAYA
}

\author{
Etty Mutiara, Winter Dewayatna, Tri Yulianto \\ Pusat Teknologi Bahan Bakar Nuklir - BATAN \\ Kawasan PUSPIPTEK Serpong Gd. 20 Tangerang Selatan, Banten 15314 \\ e-mail: emutiara@batan.go.id
}

(Naskah diterima: 19-09-2019, Naskah direvisi: 12-10-2019, Naskah disetujui: 21-10-2019)

\begin{abstract}
ABSTRAK
PEMODELAN DAN SIMULASI KINERJA PIN UJI BAHAN BAKAR PWR DENGAN UO ${ }_{2}$ DIPERKAYA. Pemodelan dan simulasi pin uji bahan bakar PWR telah dilakukan menggunakan kode komputer termomekanik FEMAXI-6. Simulasi dilakukan untuk memprediksi kinerja pin uji dengan variasi pengayaan pelet $\mathrm{UO}_{2}$. Dari simulasi ini diharapkan akan diperoleh data mengenai pengaruh tingkat pengayaan bahan bakar, fluks netron yang diterima pin uji, durasi iradiasi dan tingkat pencapaian burn-up pada awal terjadinya kontak antara pelet $\mathrm{UO}_{2}$ dengan kelongsong zircaloy (pellet cladding mechanical interaction, PCMI) pada pin uji. Data tersebut selanjutnya akan digunakan sebagai panduan pada perencanaan eksperimen iradiasi di reaktor RSG GAS Batan Serpong. Data masukan yang diterima kode FEMAXI-6 adalah geometri dan jenis material yang akan diiradiasi serta parameter kondisi iradiasi seperti flux neutron atau linear heat rate. Selanjutnya dilakukan perhitungan perpindahan panas, distribusi temperatur, lepasan gas hasil fisi serta tekanan di dalam pin bahan bakar untuk seluruh panjang bahan-bakar dalam pin uji. Distribusi temperatur yang dihasilkan dari modul analisis termal digunakan pada modul analisis mekanik rinci (PCMI, lebar gap). Hasil simulasi menunjukan kecenderungan bahwa semakin besar tingkat pengayaan uranium dalam pelet $\mathrm{UO}_{2}$, semakin cepat kontak pelet-kelongsong terjadi pada penggunaan tingkat pembangkitan daya yang relatif sama, tetapi dengan masukan Linear Heat Rate yang tinggi. PCMI belum terjadi pada iradiasi uranium alam untuk pencapaian $100 \%$ burn-up dengan daya penuh sedangkan pada pelet $\mathrm{UO}_{2}$ diperkaya $5 \%$, PCMI telah terjadi pada 900 jam iradiasi meskipun tingkat dayanya sudah diturunkan menjadi separuhnya dengan pencapaian burn-up sekitar $4 \%$.
\end{abstract}

Kata kunci : PRTF, simulasi, pin PWR, FEMAXI, unjuk kerja 


\begin{abstract}
MODELING AND SIMULATION PERFORMANCE OF ENRICHED UO ${ }_{2}$ PWR FUEL PIN TEST. Modeling and simulation of irradiation of PWR type test fuel of mini pin in RSG GAS reactor has been done using thermomechanics computer code of FEMAXI-6. The simulation was conducted by varying fuel enrichment under irradiation to predict fuel performance. The expected result from the simulation is the availability of simulation data on fuel behavior under simulated irradiation with different enrichment, neutron fluxes along the fuel, length of time and burn-up level at the beginning of contact between fuel pellets and cladding (Pellet-Cladding Mechanical Interaction, $P C M I)$. The simulation data will provide valuable information for real irradiation experiment planning in RSG GAS reactor. The input for the simulation includes geometry and materials and operation condition such as neutron fluxes and linear heat rate. The calculations include heat generated by the fuel, heat transferred out of the fuel, axial and radial distribution of temperatures along the fuel, fission gas release and also pressure generated in fuel pin for whole length of the fuel pin. Temperature distribution calculation from thermal analysis module is applied to detailed mechanical analysis module to calculate gap width between the pellet and the cladding. The simulation shows a trend for reduction of contact time between fuel and cladding with increasing enrichment level at a same reactor power level because higher enrichment will cause higher linear heat rate. While PCMI does not occur on natural uranium fuel even for $100 \%$ burnup at full power level, fuel pin containing 5\% enriched uranium causes the occurance PCMI at 900 hours of irradiation despite a reduce of power level by half with only $4 \%$ burnup.
\end{abstract}

Keywords: PRTF, simulation, PWR pin, FEMAXI, fuel performance 


\section{PENDAHULUAN}

Salah satu target PTBBN pada akhir renstra 2020-2024 adalah menghasilkan prototype pelet $\mathrm{UO}_{2}$ berderajad bakar (burnup) tinggi sebagai bahan bakar reaktor daya berpendingin air (Pressurized Water Reactor, PWR). Pada gilirannya prototype pelet $\mathrm{UO}_{2}$ diharapkan akan memperoleh kualifikasi sebagai bahan bakar siap pakai di PWR. Target tersebut dapat dipenuhi setelah prototype pelet $\mathrm{UO}_{2}$ melewati siklus litbang yang terdiri dari tahapan desain, fabrikasi, uji iradiasi dan uji pasca iradiasi pelet $\cup_{2}$. Hasil uji pasca iradiasi akan menjadi masukan bagi perbaikan desain peletUO $\mathrm{O}_{2}$ atau proses fabrikasinya sebagai tahapan awal dari siklus litbang bahan bakar berikutnya. Sebelum dilakukan uji iradiasi terhadap pelet $\mathrm{UO}_{2}$, perlu dilakukan terlebih dahulu pemodelan dan simulasi iradiasi pelet $\mathrm{UO}_{2}$ untuk memprediksi prilaku termomekanik pelet $\mathrm{UO}_{2}$ pada burn-up (fraksi bakar) tertentu yang akan menentukan umur pakainya dalam rangka pengoperasian bahan bakar yang selamat dan ekonomis di reaktor pengguna [1-8]. Hasil simulasi tersebut dapat memberikan gambaran unjuk kerja (keandalan) pelet $\mathrm{UO}_{2}[4,8-9]$ dan menjadi panduan bagi eksperimen iradiasi pin uji bahan bakarPWR pada parameter kondisi iradiasi di reaktor uji $[1,3,10]$.

Pemodelan dan simulasi unjuk kerja pelet $\mathrm{UO}_{2}$ dilakukan dengan bantuan kode komputer termomekanik bahan bakar nuklir, satu diantaranya adalah FEMAXI [1-4,1112]. Kode FEMAXI dapat digunakan untuk melakukan analisis termal seluruh panjang bahan-bakar dalam pin PWR. Analisis termal yang dilakukan meliputi perhitungan perpindahan panas, distribusi temperatur, lepasan gas hasil fisi serta tekanan di dalam pin bahan bakar [1-4]. Pada modul analisis termal tersebut, dapat dilakukan analisis mekanik sederhana menggunakan variabel seperti konduktivitas panas yang dipengaruhi oleh mekanika dari pelet dan kelongsong. Dari modul analisis termal akan dihasilkan distribusi temperatur untuk digunakan pada modul analisis mekanik rinci untuk seluruh pin dan untuk 1 pelet [1-3].

Salah satu keluaran dari simulasi menggunakan FEMAXI adalah data mengenai awal terjadinya interaksi pelet $\mathrm{UO}_{2}$ dengan kelongsong zircaloy (pelletcladding mechanical interaction, PCMI) pada parameter kondisi iradiasi dan waktu iradiasi tertentu. PCMI adalah fenomena tertutupnya celah (gap) yang ada diantara pelet $\mathrm{UO}_{2}$ dan kelongsong zircaloy sehingga terjadi kontak antara pelet dan kelongsong. PCMI menjadi salah satu constraint (batas/limit) operasi pin PWR disamping DNB (Departure from Nucleate Boiling) dan pelelehan bahan bakarterkait keselamatan dan nilai ekonomis operasi PWR $[1,4,11,13]$. PCMI pada pin PWR akan menurunkan integritas kelongsong zircaloy dengan terjadinya mulur(creep) atau retak sehingga kelongsong gagal berfungsi sebagai penghalang penting kedua bagi terlepasnya hasil fisi ke lingkungan setelah matriks pelet $\mathrm{UO}_{2}[5]$.

PCMI terjadi karena kombinasi pembesaran diameter pelet (swelling) dan diameter kelongsong yang mengecil karena mulur [4,14-15]. Pada awal iradiasi, pembelahan bahan fisil, restrukturisasi vacancy dalampelet $\mathrm{UO}_{2}$ oleh hasil fisi dan kondisi operasi pada tekanan dan temperatur tinggi menimbulkan peristiwa densifikasi pada pelet $\mathrm{UO}_{2}$ yang menyebabkan diameter pelet menyusut $[12,16]$. Densifikasi pada pelet ini diimbangi dengan pembesaran diameter pelet yang disebabkan oleh ekspansi termal dan akumulasi nuklida hasil fisi di dalam pelet. Secara total, kedua peristiwa tersebut akan menyebabkan semakin besarnya diameter pelet seiring dengan semakin besarnya burn-up bahan bakar nuklir $[12,16]$. Selain pembesaran diameter pelet pada pin uji, tekanan tinggi air pendingin akan menyebabkan penurunan diameter kelongsong sebagai akibat deformasi elastik dan mulur yang dialami kelongsong lebih besar dari ekspansi termalnya $[1,8]$. 
Peristiwa creep akan semakin memburuk seiring dengan bertambahnya waktu iradiasi sehingga diameter kelongsong akan menjadi semakin kecil $[1,8]$ Kombinasi membesarnya diameter pelet dan berkurangnya diameter kelongsong akan memperkecil celah yang ada di antara pelet dan kelongsong. Pada suatu saat celah tersebut akan hilang yang menyebabkan terjadinya kontak antara pelet dan kelongsong (PCMI) $[1,8]$.

Penelitian pemodelan dan simulasi menggunakan kode FEMAXI-6 ini dilakukan dengan tujuan untuk memahami mekanisme PCMl guna menghindari kegagalan operasi bahan bakar karena PCMI pada pin uji dengan variasi pengayaan pelet $\mathrm{UO}_{2}$. Dari penelitian ini diharapkan akan diperoleh data mengenai pengaruh tingkat pengayaan bahan bakar, fluks netron yang diterima pin uji, durasi iradiasi dan tingkat pencapaian burn-up terhadap awal terjadinya PCMI pada pin uji PWR hasil fabrikasi PTBBNBatan yangakan digunakan sebagai panduan pada perencanaan eksperimen iradiasidi reaktor uji RSG GAS Batan Serpong[3-8].Untuk skala eksperimen iradiasi, bahan bakar yang digunakan adalah versi mini dari bahan bakar yang sesungguhnya namun skala ini dapat memberikan gambaran terhadap efek iradiasi pada bahan bakar skala penuh. Setelah eksperimen iradiasi di reaktor uji, dilakukan uji pasca iradiasi untuk melihat pengaruh iradiasi terhadap kinerja bahan bakar nuklir. Bila hasil eksperimen iradiasi bahan bakar versi mini dan hasil uji paska iradiasinya memuaskan maka dapat dilakukan uji iradiasi lebih lanjut pada bahan-bakar skala penuh. Hasil-hasil eksperimen juga digunakan sebagai umpan balik bagi peningkatan akurasi simulasi dari model yang digunakan.

\section{METODOLOGI}

Algoritma penyelesaian masalah termomekanik oleh kode FEMAXI-6 digambarkan pada Gambar 1 [2].

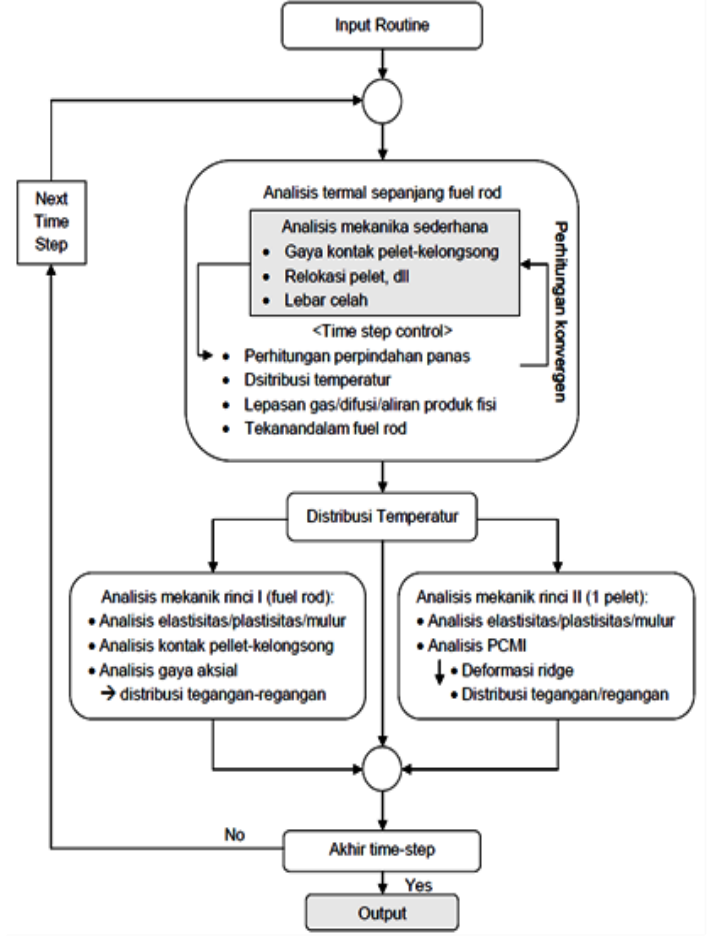

Gambar 1. Algoritma Kode FEMAXI

Data masukan (input) yang diterima kode FEMAXI-6 adalah geometri dan jenis material yang akan diiradiasi serta parameter kondisi iradiasi seperti flux neutron dan linear heat rate. Pin uji dan perangkat PRTF (Power Ramp Test Facility) yang digunakan dapat dilihat pada Gambar 2.

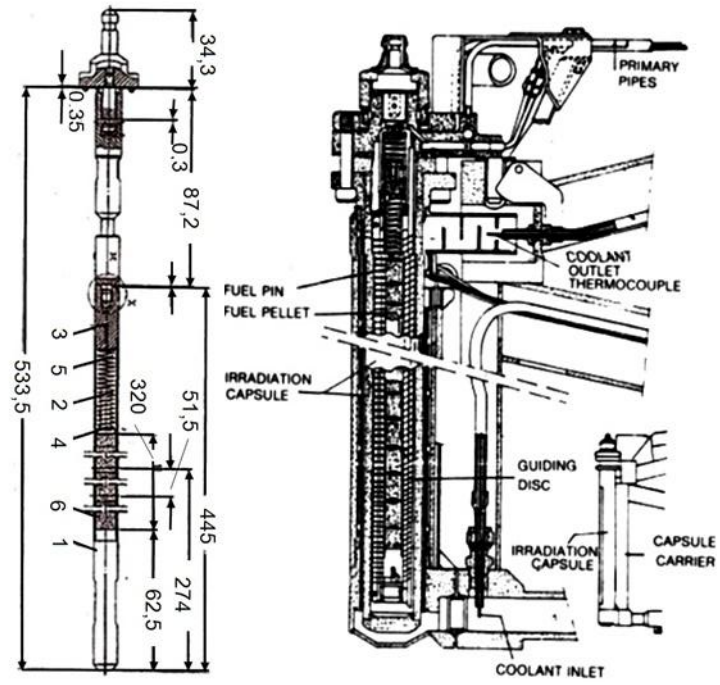

Gambar 2. Pin uji bahan bakar PWR dan perangkat PRTF 
Pin uji berupa rakitan 34 pelet dalam kelongsong zircaloy-4 dimasukkan ke dalam kapsul PRTF yang memiliki untai pendingin sendiri bertekanan 160 bar. Data pin uji termasuk pelet dan kelongsong dapat dilihat pada Tabel 1. Pin uji yang akan diiradiasi ditempatkan pada perangkat PRTF di reaktor RSG-GAS di lokasi yang ditunjukkan oleh Gambar 3. Perangkat dapat digerakkan maju mundur sepanjang posisi iradiasi PRTF untuk mendapatkan perubahan fluks neutron sehingga mampu mensimulasikan perubahan daya yang dialami oleh pin uji.

Tabel 1. Data hasil fabrikasi pin bahan bakar uji $[3,6,9,10,12]$.

\begin{tabular}{|c|c|c|c|}
\hline \multicolumn{4}{|c|}{ Pelet $\mathrm{UO}_{2}$} \\
\hline No & Parameter & Hasil Ukur & Satuan \\
\hline 1 & Diameter pelet & 9,05 & $\mathrm{~mm}$ \\
\hline 2 & Panjang pelet & 9,06 & $\mathrm{~mm}$ \\
\hline 3 & Diameter dish pelet & 0,49 & $\mathrm{~mm}$ \\
\hline 4 & Kedalaman dish atas pelet & 0,23 & $\mathrm{~mm}$ \\
\hline 5 & Kedalaman dish bawah pelet & 0,49 & $\mathrm{~mm}$ \\
\hline 6 & Densitas pelet & 94,32 & $\%$ TD \\
\hline 7 & Grain size & 6,32 & $\mu \mathrm{m}$ \\
\hline 8 & Surface Roughness pelet & 1,02 & $\mu \mathrm{m}$ \\
\hline 9 & Berat pelet & 6,31 & gram \\
\hline 10 & Berat total pelet & 214,6690 & gram \\
\hline 11 & Pengayaan & $2 ; 3 ; 4 ; 5$ & $\% U^{235}$ \\
\hline \multicolumn{4}{|c|}{ Zircaloy } \\
\hline No & Parameter & Hasil Ukur & Satuan \\
\hline 12 & Diameter luar kelongsong & 10,75 & $\mathrm{~mm}$ \\
\hline 13 & Diameter dalam kelongsong & 9,33 & $\mathrm{~mm}$ \\
\hline 14 & Surface Roughness kelongsong & $0,26-0,35$ & $\mu \mathrm{m}$ \\
\hline 15 & Panjang kelongsong & 366,5 & $\mathrm{~mm}$ \\
\hline 16 & Panjang total pin & 445,90 & $\mathrm{~mm}$ \\
\hline 17 & Volum plenum & 2067,24 & $\mathrm{~mm}^{3}$ \\
\hline 18 & Tekan gas Helium & 1 & bar \\
\hline 19 & Helium Leak Test & $6,65 \times 10^{-9}$ & mbar $\mathrm{ml} /$ detik \\
\hline
\end{tabular}

Pin uji disimulasikan dengan daya yang relatif sama menggunakan 5 variasi pengayaan uranium rendah (Low Enriched Uranium, LEU). Pin uji terdiri atas kelongsong zircaloy dengan diameter dalam $0,933 \mathrm{~cm}$ dan diameter luar $1,075 \mathrm{~cm}$ yang berisi 34 pelet $\mathrm{UO}_{2}$ yang masing-masing berdiameter $0,905 \mathrm{~mm}$ dengan tinggi $0,966 \mathrm{~mm}$. Simulasi dilakukan terhadap 5 pin uji, masing-masing berisi pelet uranium dioksida dengan pengayaan $0,7 \%$ (uranium alam), $2 \%, 3 \%, 4 \%$ dan $5 \%$. Pin uji dikenai fluks netron pada posisi $\mathrm{J} 7$ di teras reaktor RSG-GAS. Pin berisi pelet $\mathrm{UO}_{2}$ alam serta pin dengan pelet $\mathrm{UO}_{2}$ pengayaan rendah
$2 \%$ dan 3\% diberi fluks pada daya maksimum (30 MW), sementara pin uji berisi pelet $\mathrm{UO}_{2}$ pengayaan $4 \%$ dan $5 \%$ diberi fluks pada separuh daya maksimum karena jika digunakan daya maksimum, PCMI terjadi pada saat sangat awal.

Setelah data input dimasukkan, dilakukan perhitungan perpindahan panas, distribusi temperatur, lepasan gas hasil fisi serta tekanan di dalam pin bahan bakar untuk seluruh panjang bahan bakar (34 buah pelet $\mathrm{UO}_{2}$ ) dalam pin uji. Pada modul analisis termal, dapat dilakukan analisis mekanik sederhana dengan variabel seperti konduktivitas panas yang dipengaruhi oleh 
mekanika dari pelet dan kelongsong. Dari modul analisis termal akan dihasilkan distribusi temperatur untuk digunakan pada modul analisis mekanik rinci (seperti PCMI, lebar gap) yang terbagi atas modul analisis untuk seluruh pin dan untuk 1 pelet. Keluaran dari modul ini dicatat untuk setiap batasan waktunya dan digunakan sebagai masukan untuk analisis termal berikutnya dan begitu seterusnya sehingga waktu simulasi yang ditentukan tercapai.

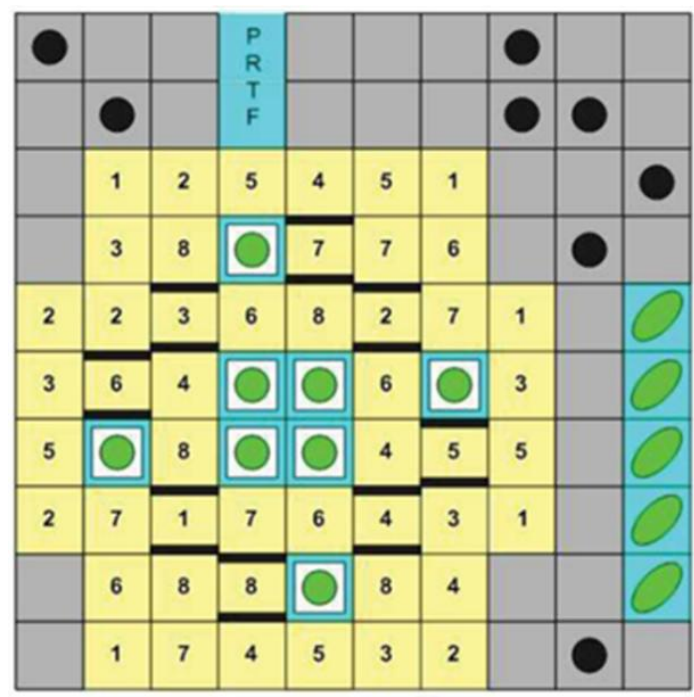

Gambar 3. Posisi PRTF di reaktor RSGGAS

\section{HASIL DAN PEMBAHASAN}

Simulasi pin uji U-alam pada rentang waktu hingga 40.000 jam pada daya penuh operasi PRTF ditunjukkan pada Gambar 4 dan Gambar 5. Daya penuh operasi PRTF adalah 30 MW. Gambar 4 menunjukkan masukan Linear Heat Rate (LHR) menurun perlahan secara asimptotis hingga nilai konstan sekitar $25 \%$ dari nilai awalnya sebesar sekitar $110 \mathrm{~W} / \mathrm{cm}$. Pembangkitan panas yang relatif konstan ini disebabkan oleh laju reaksi pembelahan dari bahan-bakar nuklir yang juga relatif konstan sehingga burn-up naik secara linier sampai akhir operasi. Pembangkitkan panas yang dialami oleh bahan bakar nuklir uranium dengan pengayaan $0,71 \%$ ( $U$ alam) dan akumulasi hasil fisi menyebabkan membesarnya diameter pelet. Peristiwa ini disertai dengan terjadinya mulur pada kelongsong zircaloy yang menyebabkan berkurangnya diameter kelongsong karena panas pembangkitan dan tekanan air pendingin. Kombinasi membesarnya diameter pelet dan berkurangnya diameter kelongsong akan memperkecil celah yang ada di antara pelet dan kelongsong. Pada saat celah tersebut hilang maka terjadi kontak antara pelet dan kelongsong (PCMI) dengan gaya kontak sekitar 5,2 MPa seperti ditunjukkan pada Gambar 5.

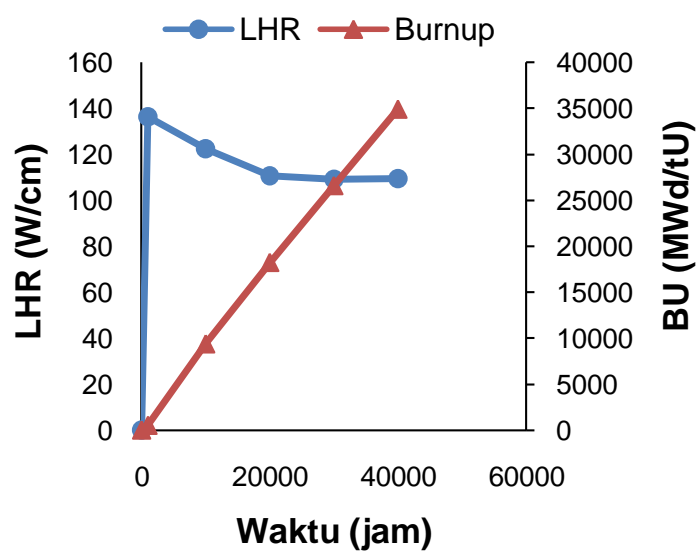

Gambar 4. Linear heat rate (LHR) dan Burnup (BU) dari pin uji uranium alam pada daya penuh selama 2200 jam.

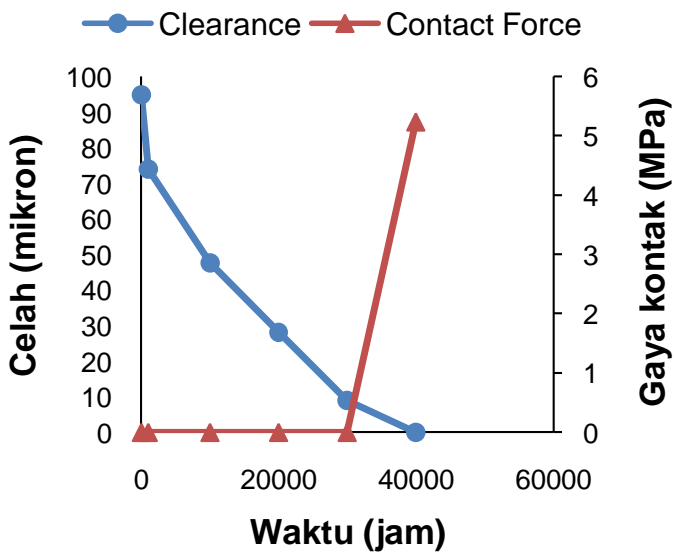

Gambar 5. Celah dan gaya kontak dari pin uji uraanium alam pada daya penuh selama 2200 jam.

Sebagaimana diperlihatkan pada gambar tersebut, kontak antara pelet dan 
kelongsong untuk pin uji dengan pelet $\mathrm{UO}_{2}$ alam pada daya penuh, terjadi pada 40.000 jam iradiasi pada saat burn-up mencapai $35.000 \mathrm{MWd} / \mathrm{tU}$, sementara burn-up total untuk pin uji berisi pelet $\mathrm{UO}_{2}$ alam adalah $7.500 \mathrm{MWd} / \mathrm{tU}$. Hasil simulasi sebagaimana yang ditunjukkan oleh Gambar 5 memberikan keyakinan bahwa sampai $100 \%$ burn-up pun belum terjadi PCMI pada pin uji yang berisi pelet $\mathrm{UO}_{2}$ alam dengan lebar celah (gap) antara pelet dan kelongsong sekitar $50 \mu \mathrm{m}$.

Simulasi pada daya penuh operasi PRTF untuk pin uji dengan pengayaan rendah $2 \%$ pada rentang waktu hingga 2.200 jam ditunjukkan pada Gambar 6 dan Gambar 7.

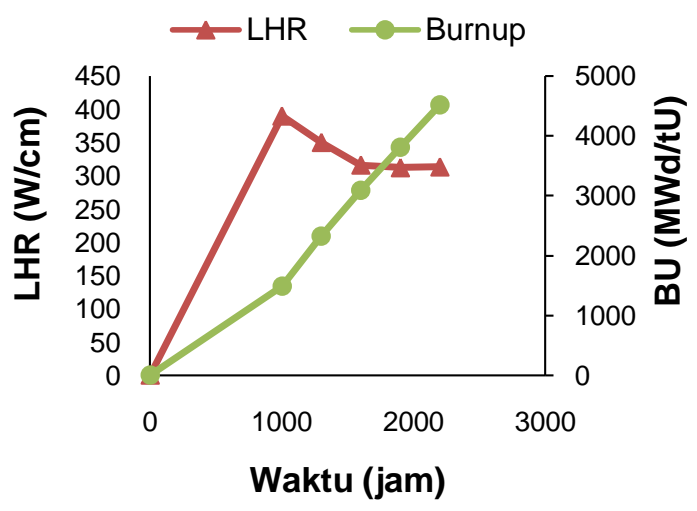

Gambar 6. Linear heat rate (LHR) dan Burnup (BU) dari pin uji pengayaan rendah $2 \%$ pada daya penuh selama 2200 jam.

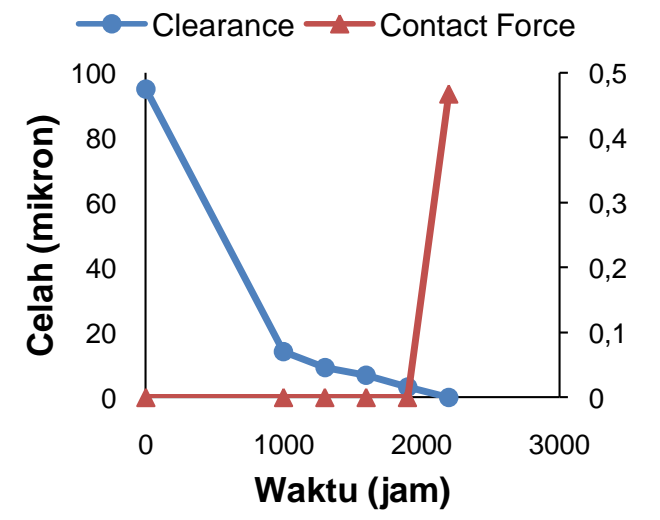

Gambar 7. Celah dan gaya kontak dari pin uji pengayaan rendah $2 \%$ pada daya penuh selama 2200 jam.
Gambar 6 menunjukkan masukan LHR menurun perlahan secara asimptotis hingga nilai konstan sekitar $25 \%$ dari nilai awalnya sebesar sekitar $310 \mathrm{~W} / \mathrm{cm}$. Pembangkitan panas yang relatif konstan ini disebabkan oleh laju reaksi pembelahan dari bahanbakar nuklir yang juga relatif konstan sehingga burn-up naik secara linier hingga akhir operasi. Pembangkitkan panas yang dialami oleh bahan bakar nuklir uranium dengan pengayaan $2 \%$ hampir tiga kali lebih besar dari bahan bakar uranium alam. Hal ini menyebabkan laju pembesaran pelet meningkat sehingga kontak antara pelet dan kelongsong terjadi lebih cepat dibandingkan kontak yang terjadi pada pelet uranium alam. Gambar 7 menunjukkan bahwa celah antara pelet dan kelongsong menurun tajam hingga $15 \mu \mathrm{m}$ pada 1000 jam operasi dan terus menurun hingga terjadi kontak antara pelet dan kelongsong pada 2200 jam. Kontak (PCMI) ini terjadi pada burn-up 4500 $\mathrm{MWd} / \mathrm{tU}$ dengan gaya kontak sebesar 0,47 $\mathrm{MPa}$.

Simulasi pada daya penuh operasi PRTF dengan pin uji pengayaan rendah $3 \%$ pada rentang waktu hingga 2200 jam ditunjukkan pada Gambar 8 dan Gambar 9.

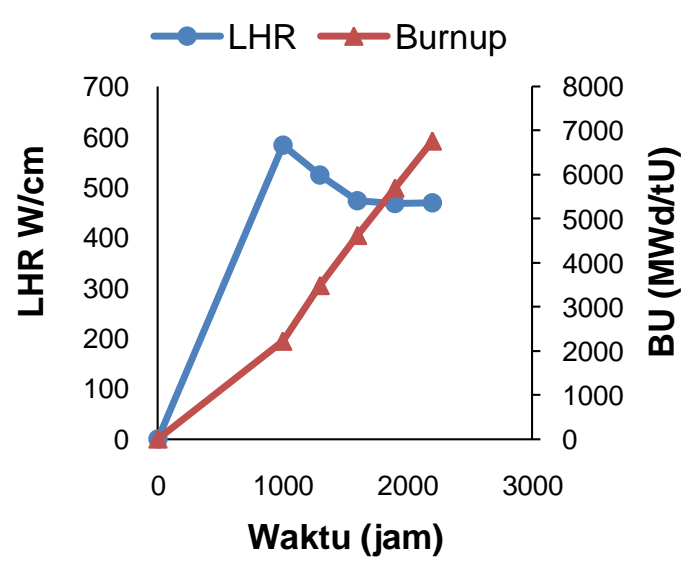

Gambar 8. Linear heat rate (LHR) dan Burnup (BU) dari pin uji pengayaan rendah $3 \%$ pada daya penuh selama 2200 jam. 


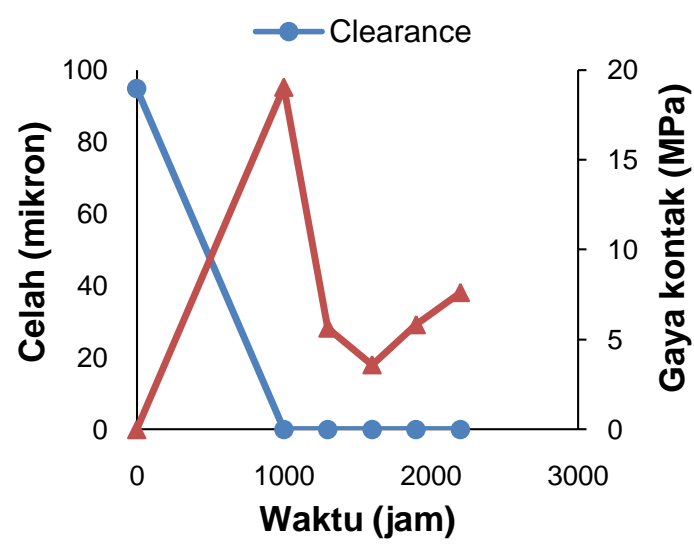

Gambar 9. Celah dan gaya kontak dari pin uji pengayaan rendah $3 \%$ pada daya penuh selama 2200 jam.

Gambar 8 menunjukkan input LHR menurun perlahan secara asimptotis hingga nilai konstan sekitar $25 \%$ dari nilai awal sebesar sekitar $470 \mathrm{~W} / \mathrm{cm}$. Simulasi PRTF pin uji pengayaan rendah $3 \%$ pada daya penuh dan masukan LHR tinggi sekitar 600 $\mathrm{W} / \mathrm{cm}$ membangkitkan panas sekitar 4 kali lebih besar dari bahan bakar uranium alam. Kondisi ini menyebabkan laju pembesaran pelet dalam pin uji menjadi lebih tinggi sehingga kontak terhadap kelongsong lebih cepat terjadi dibandingkan yang terjadi pada pelet uranium alam maupun pelet dengan pengayaan uranium $2 \%$.

Gambar 9 menunjukkan bahwa celah antara pelet dan kelongsong terus menurun hingga terjadi kontak antara pelet dan kelongsong pada 1000 jam operasi dengan burn-up yang baru mencapai 2200 $\mathrm{MWd} / \mathrm{tU}$, sekitar 6,3\% burn-up total. Masukan LHR sebesar $600 \mathrm{~W} / \mathrm{cm}$ dengan fluks netron pada daya penuh (30MW) untuk simulasi PRTF pin uji pengayaan rendah 3\% dimaksudkan agar waktu iradiasi simulasi lebih singkat. Nilai LHR ini terlalu tinggi bila dibandingkan dengan LHR pada operasi normal sebenarnya di PWR Westinghouse yang dibatasi sampai dengan $13,6 \mathrm{~kW} / \mathrm{ft}$ $(448 \mathrm{~W} / \mathrm{cm})$ [17]. LHR dibatasi untuk menghindari terjadinya hot spot lokal pada bahan bakar yang menerima fluks netron tinggi sehingga tidak terjadi PCMI dini pada pin di awal operasi [7,11,17-19]. Simulasi untuk menghindari terjadinya PCMI dalam pencapaian burn-up tinggi telah dilakukan untuk reaktor daya BWR (Boiling Water Reactor) melalui pengkondisian bahan bakar dan pengaturan parameter operasi untuk operasi reaktoryang selamat dan ekonomis menggunakan kode FEMAXI-5 [11]. Pengkondisian bahan bakar yang dimaksud disini adalah pengaturan parameter operasi reaktor, salah satunya adalah LHR, agar fenomena densifikasi dan relaksasi stress pada pelet bahan bakar dapat dikendalikan secara bertahap. Pengkondisian ini dapat menurunkan gaya kontak antara pelet-kelongsong di awal terjadinya PCMI yang selanjutnya akan membuka kembali gap antara pelet-kelongsong. Sebagaimana ditampilkan Gambar 8 dan Gambar 9, gaya kontak antara pelet-kelongsong turun sejalan dengan turunnya LHR pada simulasi pin uji pin uji pengayaan rendah $3 \%$. Apabila tidak dilakukan pengkondisian bahan bakar maka fenomena PCMI yang terjadi akan memburuk dengan membiarkan proses swelling bahan bakar yang terus berlanjut yang semakin meningkatkan gaya kontak di area $\mathrm{PMCl}$ dan mereduksi celah antara pelet-kelongsong pada pelet $\mathrm{UO}_{2}$ lainnya dalam pin [11].

Simulasi pada setengah dari daya penuh operasi PRTF dengan pin uji pengayaan rendah $4 \%$ pada rentang waktu hingga 2.200 jam ditunjukkan pada Gambar 10 dan Gambar 11.

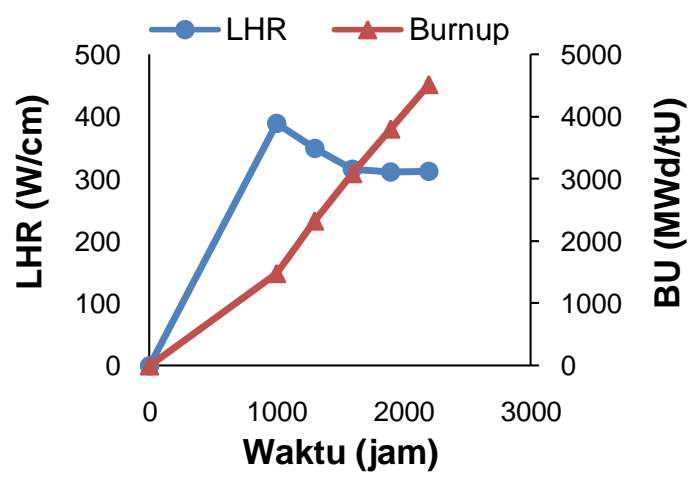

Gambar 10. Linear heat rate (LHR) dan Burnup (BU) dari pin uji pengayaan rendah 4\% pada daya penuh selama 2.200 jam. 


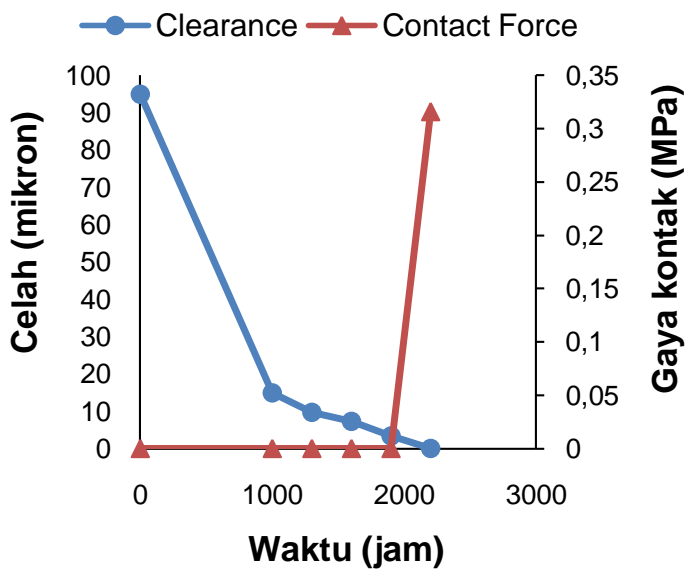

Gambar 11. Celah dan gaya kontak dari pin uji pengayaan rendah $4 \%$ pada daya penuh selama 2200 jam.

Simulasi dilakukan pada setengah daya penuh karena PCMI segera terjadi pada saat-saat awal operasi jika simulasi pin uji pengayaan rendah $4 \%$ menggunakan daya penuh operasi PRTF.

Gambar 10 menunjukkan masukan LHR menurun perlahan secara asimptotis hingga nilai konstan sekitar $25 \%$ dari nilai awalnya sebesar sekitar $300 \mathrm{~W} / \mathrm{cm}$. Pada pengayaan ini fluks neutron diturunkan hingga setengah dari fluks neutron yang digunakan pada iradiasi pin dengan pelet berpengayaan uranium alam hingga pengayaan 3\% untuk menghindari terjadinya kontak pelet-kelongsong (PCMI) pada waktu yang sangat cepat bila digunakan fluks neutron pada daya penuh. Melalui penurunan daya ini, maka kontak pelet kelongsong terjadi pada 2.200 jam iradiasi (ditunjukkkan pada Gambar 11), durasi iradiasi yang sama untuk terjadinya kontak pelet kelongsong untuk pin uji dengan pengayaan uranium $2 \%$. Kontak ini terjadi pada pencapaian $21 \%$ burn-up untuk pin uji dengan pengayaan uranium $2 \%$.Bila dibandingkan dengan pin uji pengayaan rendah 3\% ternyatakontak pelet kelongsong pada pengayaan $4 \%$ ini terjadi pada waktu yang lebih lama, hal ini disebabkan fluks yang diterima oleh pin uji pengayaan $4 \%$ hanya separuhnya. Dengan inputan LHR yang lebih rendah (separuh daya penuh),
PCMI pin uji berisi pelet $\mathrm{UO}_{2}$ pengayaan $4 \%$ terjadi pada waktu mencapai $10 \%$ burn-up, sementara untuk pin dengan pengayaan $3 \%$, PCMI sudah terjadi pada burn-up yang baru mencapai $6,3 \%$ dengan iradiasi daya penuh.

Simulasi pada setengah dari daya penuh operasi PRTF dengan pin uji pengayaan rendah $5 \%$ pada rentang waktu hingga 1000 jam ditunjukkan pada Gambar 12 dan Gambar 13. Simulasi dilakukan pada setengah daya penuh karena PCMI segera terjadi pada saat-saat awal.

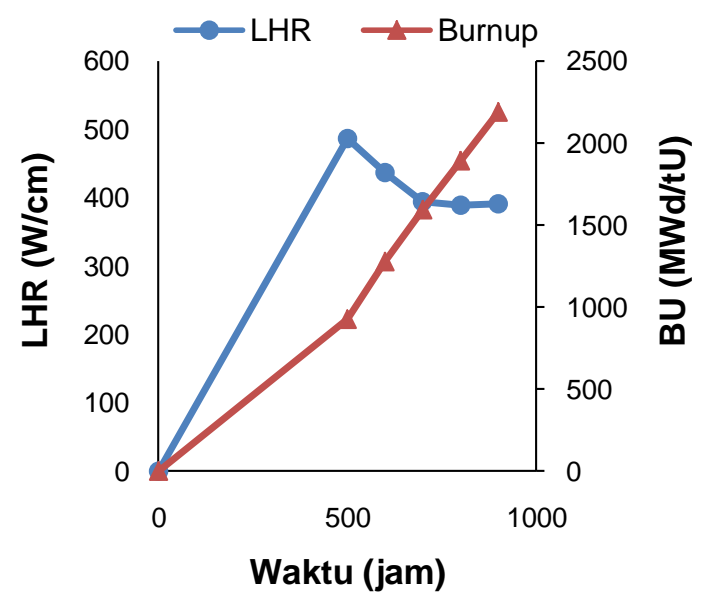

Gambar 12. Linear heat rate (LHR) dan Burnup (BU) dari pin uji pengayaan rendah $5 \%$ pada daya penuh selama 2.200 jam.

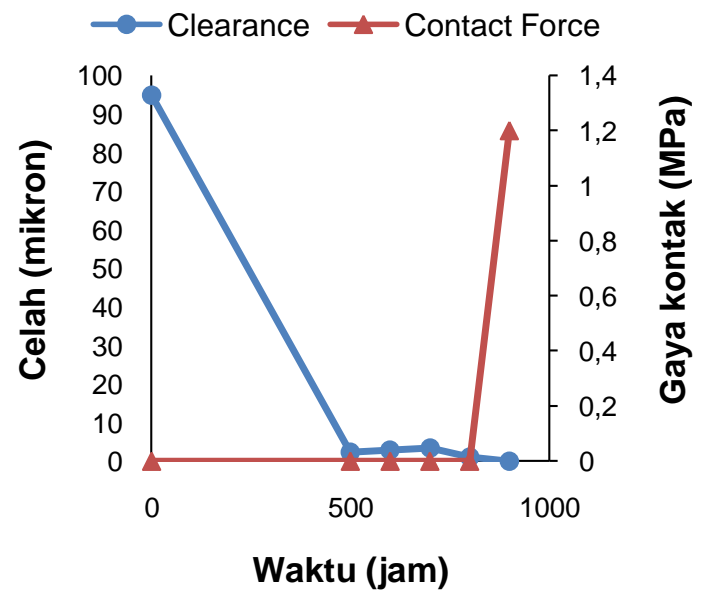

Gambar 13. Celah dan gaya kontak dari pin uji pengayaan rendah $5 \%$ pada daya penuh selama 2200 jam. 
Gambar 12 menunjukkan bahwa panas yang dibangkitkan sepanjang pin mula-mula agak tinggi dan turun sedikit ke suatu nilai konstan pada akhir simulasi, sedangkan burn-up terus naik secara linier hingga akhir operasi. Sedangkan Gambar 13 menunjukkan bahwa meskipun fluks netron telah diturunkan hingga setengah dari fluks yang diterima oleh pin uji dengan pelet berpengayaan uranium 3\% akan tetapi kontak antara pelet dan kelongsong terjadi pada waktu yang lebih singkat yaitu pada 900 jam, waktu yang lebih singkat dari waktu kontak untuk pelet bahan bakar nuklir berpengayaan 3\% yaitu sebesar 1000 jam.

\section{SIMPULAN}

Prediksi kinerja pin uji PWR di PRTF
dengan pemodelan dan simulasi
menggunakan kode termomekanik FEMAXI-
6 memberikan data bahwa kontak antara
pelet UO $_{2}$ dan $\quad$ kelongsong
zircaloy(PCMI)sangat dipengaruhi oleh
pengayaan uranium. Hasil simulasi pada
penggunaan tingkat pembangkitan daya
yang relatif sama, tetapi dengan masukan
Linear Heat Rate yang tinggi memberikan
kecenderungan bahwa semakin besar
tingkat pengayaan uranium dalam pelet
UO ${ }_{2}$, semakin cepat kontak pelet-
kelongsong terjadi. PCMI belum terjadi pada
iradiasi uranium alam untuk pencapaian
$100 \%$ burn-updengan daya penuh
sedangkan pada pelet UO ${ }_{2}$ diperkaya $5 \%$,
PCMI telah terjadi pada 900 jam iradiasi
meskipun tingkat dayanya sudah diturunkan
menjadi separuhnya dengan pencapaian
burn-upsekitar $4 \%$. Data hasil simulasi ini
selanjutnya akan dijadikan panduanbagi
penyusunan rencana eksperimen iradiasi
Pin Uji Bahan Bakar PWR menggunakan
perangkat PRTF di reaktor RSG GAS.

\section{UCAPAN TERIMA KASIH}

Kami mengucapkan terima kasih kepada Kepala BFBBN dan semua staf yang telah membantu dalam menyelesaikan tulisan ini.

\section{DAFTAR PUSTAKA}

[1] P. Van Uffelen, J. Hales, W. Li, G. Rossiter, R. Williamson, "A review of fuel performance modelling," Journal of Nuclear Materials, vol. 516, hal. 373412, 2019.

[2] M. Suzuki, H. Saitou, Y. Udagawa and F. Nagase, "Light water reactor fuel analysis code, FEMAXI-7: Model and structure, JAEA-Data/Code, 2013-005.

[3] P. Van Uffelen, and M. Suzuki,3.19: Oxide fuel performance modeling and simulations," Comprehensive Nuclear Materials, vol. 3, no.19, pp. 535-577, 2012.

[4] M. Imani, M. Aghaie, A. Zolfaghari, A. Minuchehr, "Numerical study of fuelclad mechanical interaction during longterm burnup of WWER1000," Annals of Nuclear Energy, vol. 80, hal. 267-278, 2015.

[5] H. C. Kim, S. K. Seo, S. U. Lee, Y. S. Yang, "Development of NUFORM3D module with FRAPCON 3.4 for simulation of pellet-cladding mechanical interaction," Nuclear Engineering and Design, vol. 318, hal. 61-71, 2017.

[6] X. Gong, Y. Jiang, S. Ding, Y. Huo, L. Yang, "Simulation of the in-pile behaviors evolution in nuclear fuel rods with the irradiation damage effects," Acta Mechanica Solida Sinica, vol. 27, no 6, pp. 551-567, 2014.

[7] R. L. Williamson, N. A. Capps, W. Liu, Y. R. Rashid, B. D. Wirth, "Multidimensional simulation of LWR fuel behavior in the BISON fuel performance code," The Journal of The Minerals, Metals and Materials Society, vol. 68, no.11, pp. 2930-2937, 2016.

[8] L. Van Brutzel, R. Dingreville, T.J. Bartel, "Chapter 2. Nuclear fuel deformation phenomena, NEA/NSC/R(2015)5, CEA, France.

[9] Y.Guérin, "Modeling fuel behavior, Nuclear fuels - DENMonographs, 
CEA/DEN Direction scientifique, CEA Saclay (France), pp. 29-30, 2009.

[10] J. Susilo, T. M. Sembiring, W. Dewayatna, "Irradiation characteristic of natural $\mathrm{UO}_{2}$ pin PHWR target at PRTF facilities of RSG-GAS Core," Jurnal Teknologi Reaktor Nuklir Tri Dasa Mega, vol. 19, no. 2, hal. 71-82, 2017.

[11] H. H. Lopez, and M. A. Lucatero, "BWR fuel rod behavior evaluation for preconditioning power ramps with FEMAXI-V," Annals of Nuclear Energy, vol. 38, no. 10, pp. 2213-2217, 2011.

[12] V. Krasnorutskyy, and O. Slyeptsov, "Investigation of PWR and VVER fuel rod performances under high burnup using FEMAXI \& PAD codes," Progress Report, IAEA Research Contract No.15370, 2008.

[13] M. Piro, D. Sunderland, S. Livingstone, J. Sercombe, C. Judge, "A review of pellet-clad interaction behavior in zirconium alloy fuel cladding," Reference Module in Materials Science and Materials Engineering, 2017.

[14] A. Gojan, "Advanced modeling of pelletcladding interaction," Master of Science Thesis, KTH Royal Institute of Technology, Stockholm, Sweden, 2016
[15] B. Michel, J. Sercombe, C. Nonon, and O. Fandeur, "Modeling of Pellet Cladding Interaction," Reference Module in Materials Science and Materials Engineering, CEA, DEN, DEC, 2016.

[16] M. E. Cazado, and A. C. Denis, "Model of nuclear fuel pellets densification under irradiation and isothermal conditions: Application to $\mathrm{UO}_{2}$ fuels," Journal of Nuclear Materials, vol. 510, hal. 585-595, 2018.

[17] NRC, 2.2 Power Distribution Limit, 0519 - R304P - Westinghouse Technology System Manual, 2012, available :https://www.nrc.gov/docs/ML1122/ML1 1223A208.pdf

[18] N. Capps, M. Kennard, W. Liu, B. D. Wirth, J. Rashid, "PCMl analysis of a commercial PWR using BISON fuel performance code," Nuclear Engineering and Design, vol. 324, pp. 131-142, 2017.

[19] N. Capps, A. Mai, M. Kennard, W. Liu, "PCMI analysis of Zircaloy coated clad under LWR steady state and reactor startup operations using BISON fuel performance code," Nuclear Engineering and Design, vol. 332, pp. 383-391, 2018. 
